\title{
Chemoselectivity Investigation on Arylations Using Diaryliodonium Salts
}

\author{
Joel Malmgren, Nazli Jalalian, Berit Olofsson*
}

Department of Organic Chemistry, Arrhenius Laboratory, Stockholm University, 10691 Stockholm, Sweden

*e-mail corresponding author:berit@organ.su.se

Keywords: Regioselectivity, diaryliodonium salts, arylation

\section{INTRODUCTION}

Arylations are important transformations in organic synthesis. Aryl ethers, aryl esters and a-aryl carbonyl compounds are important substructures in a variety of compounds such as pharmaceuticals and natural products. ${ }^{1}$

Diaryliodonium salts have recently been recognized as versatile reagents in organic synthesis. ${ }^{2}$ They can be employed both in metal mediated and metal-free reactions thereby avoiding the potential drawbacks of organometallic chemistry such as toxicity and high cost. $^{3}$

Efficient one-pot procedures to diaryliodonium salts have been developed within our group (Scheme 1) increasing the availability of these compounds. ${ }^{4}$

Scheme 1. One-pot routes to diaryliodonium salts

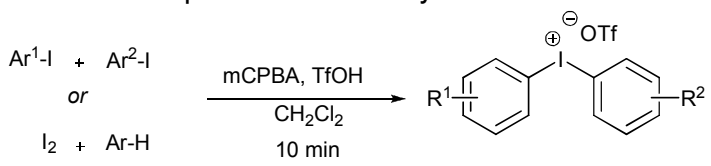

With fast and non-expensive procedures for the preparation of these salts in hand we are currently investigating the electrophilic arylating potential of these reagents. The results from a chemoselectivity investigation where different nucleophiles have been arylated using unsymmetric salts are presented.

\section{RESULTS AND DISCUSSION}

Unsymmetric diaryliodonium salts are sometimes preferred due to economic and accessibility problems. For these reasons it is important to get a clear understanding of the chemoselectivity. The expected outcome is that electron deficient aryls will be transferred over electron-rich aryls ${ }^{5}$ and also that steric bulk in the ortho-positions will favor transfer of that aryl. However, when metals are involved sterics are expected to control the outcome, transferring the aryl with the least steric bulk (Scheme 2). ${ }^{6}$

These rules of thumb however, cannot always be applied and we would like to know how to use these effects to be able to design diaryliodonium salts that are highly chemoselective.
Scheme 2. Arylation of an arbitrary nucleophile with and without a metal catalyst

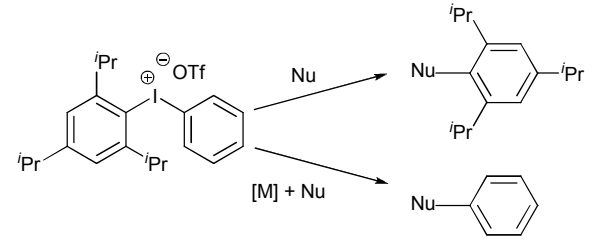

We are currently investigating the chemoselectivity of a series of unsymmetric diaryliodonium salts reacting with various nucleophiles (figure 1).

Figure 1. Examples of nucleophiles and diaryliodonium triflates

Nucleophiles<smiles>[R]C(=O)O</smiles><smiles></smiles><smiles>CCOC(=O)C(C)C(=O)OCC</smiles>

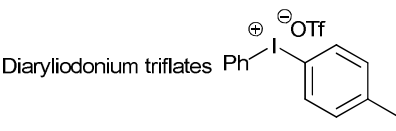<smiles>Cc1ccc([Hg](=O)(O)c2ccccc2)c(C)c1</smiles><smiles>Cc1cc(C)c([Hg]([O-])([O-])c2ccccc2)c(C)c1</smiles>

Our results so far indicate that ortho-substituted aryls are preferentially transferred.

\section{ACKNOWLEDGEMENTS}

This work was financially supported by the Swedish Research Council, STINT, K \& A Wallenberg Foundation.

\section{REFERENCES}

1. (a) Lloyd-Jones, G. C., Angew. Chem. Int. Ed. 2002, 41 (6), 953; (b) Boger, D. L.; Miyazaki, S.; Kim, S. H.; Wu, J. H.; Castle, S. L.; Loiseleur, O.; Jin, Q., J. Am. Chem. Soc. 1999, 121 (43), 10004.

2. Ciana, C. L.; Phipps, R. J.; Brandt, J. R.; Meyer, F. M.; Gaunt, M. J., Angew. Chem. Int. Ed. 2011, 50 (2), 458.

3. Merritt, E. A.; Olofsson, B., Angew. Chem. Int. Ed. 2009, 48 (48), 9052.

4. (a) Bielawski, M.; Aili, D.; Olofsson, B., J. Org. Chem. 2008, 73 (12), 4602; (b) Bielawski, M.; Zhu, M.; Olofsson, B., Adv. Synth. Cat. 2007, 349 (17-18), 2610; (c) Merritt, E. A.; Malmgren, J.; Klinke, F. J.; Olofsson, B., Synlett 2009, (14), 2277; (d) Zhu, M. Z.; Jalalian, N.; Olofsson, B., Synlett 2008, (4), 592.

5. Petersen, T. B. Khan, R.; Olofsson, B. Submitted

6. Phipps, R. J.; Gaunt, M. J., Science 2009, 323 (5921), 1593. 